(6)

\section{OPEN ACCESS}

'Department of Government, Harvard University, Cambridge, Massachusetts, USA

${ }^{2}$ Columbia University, New York, New York, USA

${ }^{3}$ Building Markets, Monrovia, Liberia

${ }^{4}$ Beedie School of Business,

Simon Fraser University,

Vancouver, Canada

\section{Correspondence to}

Professor Jonas Hjort,

Columbia University, Uris Hall, 3022 Broadway, Room 622 New York, NY 10027, USA; hjort@columbia.edu

Received 27 April 2015 Revised 10 September 2015 Accepted 14 September 2015 Published Online First 5 October 2015

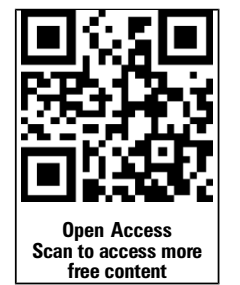

\title{
Ebola, jobs and economic activity in Liberia
}

\author{
Jeremy Bowles, ${ }^{1}$ Jonas Hjort, ${ }^{2}$ Timothy Melvin, ${ }^{3}$ Eric Werker ${ }^{4}$
}

\section{ABSTRACT \\ Background The 2014 Ebola virus disease (EVD)} outbreak in the neighbouring West African countries of Guinea, Liberia and Sierra Leone represents the most significant setback to the region's development in over a decade. This study provides evidence on the extent to which economic activity declined and jobs disappeared in Liberia during the outbreak.

Methods To estimate how the level of activity and number of jobs in a given set of firms changed during the outbreak, we use a unique panel data set of registered firms surveyed by the business-development non-profit organisation, Building Markets. We also compare the change in economic activity during the outbreak, across regions of the country that had more versus fewer Ebola cases in a difference-in-differences approach.

Findings We find a large decrease in economic activity and jobs in all of Liberia during the Ebola outbreak, and an especially large decline in Monrovia. Outside of Monrovia, the restaurants, and food and beverages sectors have suffered the most among the surveyed sectors, and in Monrovia, the construction and restaurant sectors have shed the most employees, while the food and beverages sectors experienced the largest drop in new contracts. We find little association between the incidence of Ebola cases and declines in economic activity outside of Monrovia.

Conclusions If the large decline in economic activity that occurred during the Ebola outbreak persists, a focus on economic recovery may need to be added to the efforts to rebuild and support the healthcare system in order for Liberia to regain its footing.

\section{BACKGROUND}

The 2014 Ebola virus disease (EVD) outbreak in the neighbouring West African countries of Guinea, Liberia and Sierra Leone represents the most significant setback to the region's development in over a decade. With over 20000 confirmed cases and more than 10000 casualties of the disease reported by the end of 2014, it is the worst ever recorded outbreak of the virus and has caused chaos in some of the world's poorest countries.

In Liberia, the first suspected cases of Ebola were reported by the Ministry of Health to the WHO in March 2014. Despite some early calls for a national and international response, the virus spread faster than authorities' ability to isolate victims and trace contacts. The spread of the disease prompted a substantial government response in July 2014, when measures were put in place to begin tackling the outbreak, including a state of emergency declared by President Ellen Johnson Sirleaf (figure 1).

Even with those measures, the cumulative number of Ebola cases in Liberia passed 8000 by the end of 2014. New cases have slowly declined in recent months, with just a handful of Ebola cases in Liberia since April 2015. ${ }^{1}$ As the disease itself has come under control, the longer term issue of its economic implications has taken centre stage.

The aim of our study is to provide evidence on the impact of the Ebola outbreak on jobs and economic activity - in particular, changes in economic outcomes during the outbreak and the connection between the regional incidence of the virus and economic outcomes. This is important for several reasons.

First, the magnitude and regional incidence of the economic impact has important implications for individual well-being and the policy response. In the context of the 2014 Ebola outbreak, revised World Bank estimates suggest that over $\$ 1.6$ billion of output in Liberia, Sierra Leone and Guinea will be forgone in $2015 .^{2}$ Such macrolevel estimates are important for forecasting the outbreak's aggregate impacts, but rely heavily on the assumptions underlying the predictive model used. In addition to providing a more detailed picture of the economic decline based on ground-level data from the outbreak in question, new evidence from microlevel studies can thus feed into and improve macroeconomic modelling approaches; right now, there is very little such evidence. An important exception is Glennerster and Suri, ${ }^{3}$ who found that the number of agricultural traders in Sierra Leone had sharply fallen compared to before the outbreak. The present study is unique in that we have access to pre-outbreak baseline data on firms, which allows us to estimate changes in economic activity during the outbreak. Comparing the regional incidence of the economic downturn and Ebola itself can also help inform policy responses.

Second, existing literature argues that the economic impact of epidemics may have long-term consequences. While the empirical evidence is primarily on the impact of AIDS on educational attainment, ${ }^{\mathrm{i}}$ it is possible that jobs and contracts lost will take time to reappear.

Finally, jobs and economic activity are, in turn, believed to affect long-term health. Cutler et $a l^{\dagger}$ found strong cross-country correlations between income per capita and mortality rates, correlations also found within countries over time. Stuckler et $a l^{8}$ found that the sensitivity of mortality to economic crises depends heavily on differences in social protection, suggesting that knowledge on the

${ }^{\mathrm{i}} \mathrm{Kalemli-Ozcan}{ }^{4}$ found that the spread of AIDS led to lower school enrolments and higher fertility in a panel of African countries, and Evans and $\mathrm{Miguel}^{5}$ observed that AIDS orphans in Kenya have lower educational attainments. Thirumurthy et $a l^{6}$ found that ARV treatment of AIDS could increase labour force participation and hours worked. 


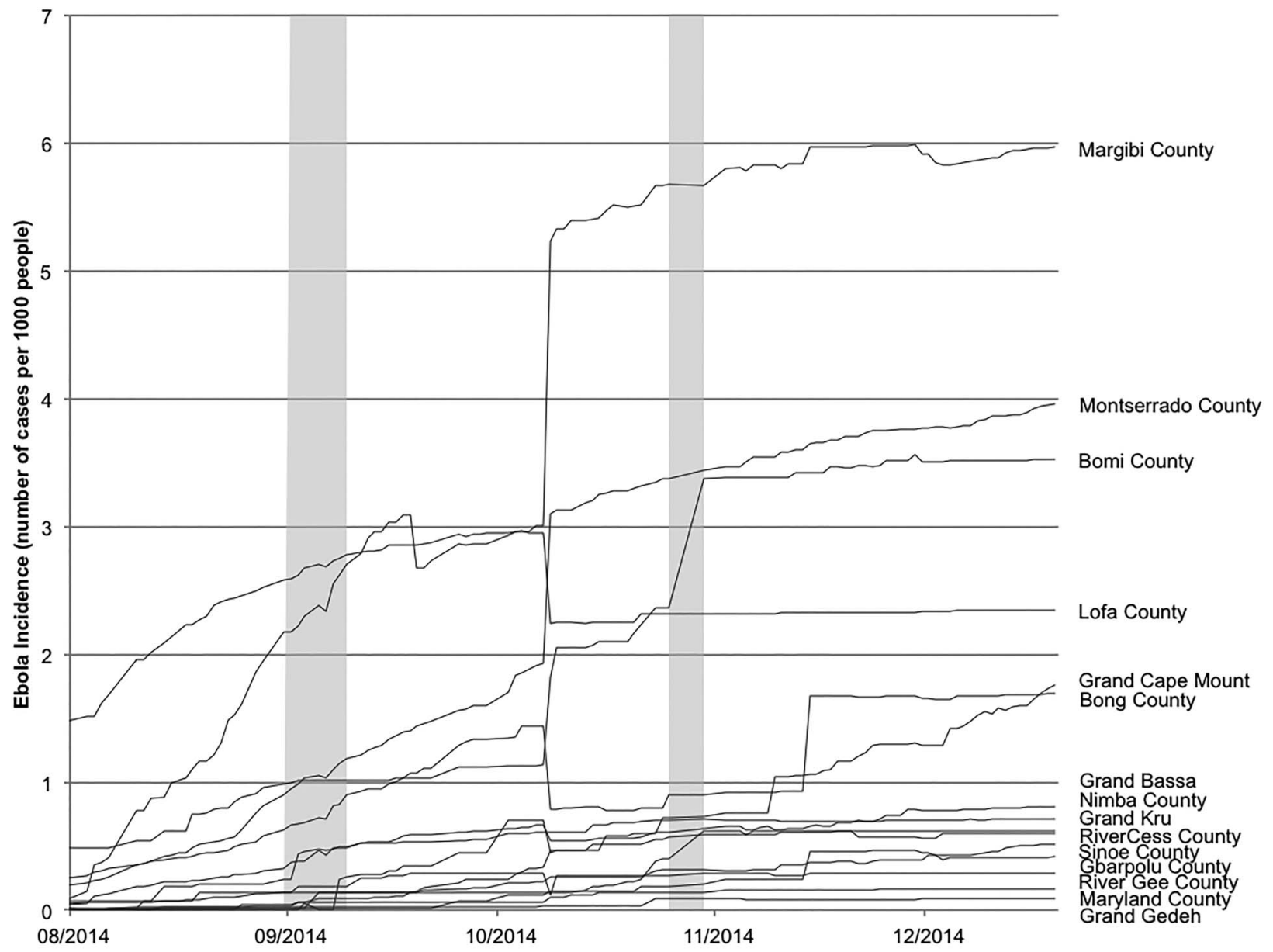

Figure 1 Evolution of cumulative cases (per 1000 people) across Liberian counties.

economic impact of Ebola that enables better targeting and design of the policy response can have considerable benefits.

\section{METHODS \\ Design}

We estimate the change in firm-level economic activity and number of jobs during the outbreak, relative to a pre-outbreak baseline, and compare the changes across more versus less Ebola-affected regions of Liberia. Using a panel data set allows us to benchmark the level of economic activity during the outbreak against the level seen in the same firms prior to the outbreak, as well as to conduct a difference-in-differences analysis comparing the regional incidence of the economic decline to that of Ebola cases. Difference-in-differences models are commonly used in economics and other social sciences because they allow researchers to control for time-invariant differences between units/regions (eg, permanently better economic outcomes in some regions) and location-invariant differences between periods (eg, changes in monetary policy).

If there are no differential trends in outcomes across 'treatment' and 'control' units/regions, a differences-in-differences specification will estimate the causal effect of the outbreak in more-affected regions, relative to less-affected regions. This assumption may not hold in our setting: the less-affected counties might also be more disconnected from the global and regional economy and thus on a slower/less volatile growth path (and less likely to respond to any shock). Moreover, even if the assumption of 'no differential trends' holds, the outbreak may affect all regions irrespective of their disease intensity (eg, due to reduced mobility and trade) and/ or Ebola-related expenditures might drive some economic activity, in which case our estimates would not capture an isolated 'Ebola effect'. Ultimately, we view our difference-in-differences results as simply comparing the incidence of Ebola cases and economic decline during the outbreak across different regions of Liberia.

Table 1 Frequency of regions and sectors in sample

\begin{tabular}{lccccc}
\hline & Automotive & Construction & Food and Beverages & Restaurants & Total \\
\hline Less-affected counties & 8 & 47 & 52 & 20 & 98 \\
Montserrado & 15 & 47 & 43 & 16 & 110 \\
More-affected counties & 15 & 61 & 70 & 10 & 129 \\
Total & 38 & 155 & 165 & 46 & \\
\hline
\end{tabular}

Note that the sum of the columns is greater than the sum of the rows. This is because some firms are registered as providing goods and services under more than one of our four sectors. 
Such a comparison is important because it may help inform the policy response to the 2014 and future outbreaks, and because it may speak to the channels through which epidemics can affect economic activity. While distinguishing between such channels is beyond the scope of this paper, some plausible mechanisms-for example, people staying home to avoid contact with infected individuals-would suggest that decreases in economic activity should occur primarily where Ebola cases have been reported, while other channels—for example, general fear and uncertainty-would not necessarily imply such a prediction.

Pre-outbreak, baseline data on a sample of Liberian firms comes from the non-profit organisation, Building Markets (BM). BM works to facilitate contracts and business between local firms and large buyers (eg, multinational corporations and government agencies) in Liberia and other developing countries. To be listed as a supplier on BM's online portal, firms must be formally registered with the government; operational and able to deliver goods and services; and answer a comprehensive survey on many aspects of their business-including past contracts, employment, etc. When the Ebola outbreak hit, BM had visited and verified just over $25 \%$ of the 12642 firms that were formally registered in 2013.

Working with data from BM has two advantages for our research. First, we use the BM portal as a sampling frame, as explained below. Second, and more importantly, the preoutbreak surveys can be used as baseline data.

\section{Sampling}

We constructed three groups of Liberian counties based on the number of Ebola cases per 1000 people in each county in September 2014. ${ }^{\text {ii }}$ We classified Lofa, Margibi, Bomi and Bong as the 'more-affected counties'; Nimba, Grand Bassa, Grand Cape Mount and Grand Gedeh as 'less-affected counties'; and Montserrado (where Monrovia, the capital, is located) as a category of its own, though its Ebola rates place it in the middle of the most-affected counties. See figure 1 for a graphical justification for these categories, where the grey background bars represent the time periods over which the follow-up survey data were collected. We selected four sectors to focus on: automotive, construction, food and beverages, and restaurants.

We then drew a random sample of the firms in BM's portal, stratifying on these two dimensions (county and sector), and oversampling smaller cells. The number of sample firms in each cell is shown in table 1 .

\section{Outcome variables}

We chose outcome variables with both high economic relevance and good coverage in the baseline data: first, whether the firm had closed; second, the number of people employed by each firm and third, a binary question of whether the firm had won any contracts in the past 6 months. The outcome variables can be interpreted as one direct measure of firm activity (winning contracts) and two of its consequences (firm closure and jobs per firm).

We attempted to contact firms in the baseline twice after the start of the crisis-once in mid-September and again in early November 2014. From the baseline of 402 firms, data from 337 firms were successfully collected in at least one of the follow-up surveys, representing a high response rate of

${ }^{i i}$ Case counts are available from the Ministry of Health's daily situation reports, and population data can be obtained from the 2008 census.
Table 2 Baseline statistics

\begin{tabular}{lll}
\hline Variable & Mean & S.D. \\
\hline Total number of employees & 8.90 & 14.62 \\
Number of permanent employees & 4.58 & 5.14 \\
Number of temporary employees & 4.32 & 12.77 \\
Won contract in the past 6 months & 0.53 & 0.50 \\
Value of contracts won in the past 6 months (\$) & 25366 & 79226 \\
Number of clients & 6.74 & 15.81 \\
Revenue in last month (\$) & 24922 & 66799 \\
\hline
\end{tabular}

These summary statistics are compiled using the last pre-Ebola observation for each of the 337 firms in the final data set. Note, the variables that we do not use as outcomes are missing for many firms at baseline (eg, only 65/337 firms report sales).

84\%. ${ }^{\text {iii }}$ Importantly, no questions that explicitly mentioned Ebola were asked, so as to avoid response priming.

Unfortunately, the data do not allow us to calculate baseline firm closure rates in Liberia among our sample of firms, but only to compare how many firms closed across different regions and sectors during the crisis. ${ }^{\text {iv }}$

The majority of the pre-outbreak, baseline surveys were conducted between early 2012 and mid-2013. Table 2 provides descriptive statistics from the baseline.

\section{Analysis}

We report simple t tests of equality of proportions for the firm closure outcome. For the other two outcome variables, closed firms are included in the follow-up data with zero employees and no recently won contracts. We use clustered SEs at the firm level in all regressions. ${ }^{\mathrm{v}}$ For the outcome variable that is the logarithm of the total number of employed individuals per firm, we report estimates from three specifications: an ordinary least squares (OLS) regression (column I), an OLS regression with firm fixed effects (column II) and a tobit regression (to account for censoring at zero) (column III). For the winning contracts outcome variable, we report results from a linear probability model (column IV), a linear probability model with firm fixed effects (column V) and a logit regression (since the outcome variable is binary) (column VI). In all regressions, quarter fixed effects are included to account for seasonality.

\section{RESULTS}

\section{Firm closure}

Out of all firms in the baseline data successfully reached in at least one follow-up survey, $12 \%$ report to have closed down. Across sectors, $8 \%$ of automotive firms, $8 \%$ of construction firms, $15 \%$ of food and beverages firms, and 30\% of restaurants in the sample have closed since the crisis.

Of the firms surveyed in less-affected counties, 10\% have closed down. Of the firms in Montserrado, 20\% have closed

\footnotetext{
iii Characteristics that predict the firm not being reached in the surveys conducted during the Ebola outbreak appear unrelated to the probability of firm closure, and the results of the next section hold if we treat such firms as closed.

${ }^{\text {iv }}$ The survey protocol for designating a firm as 'closed' was more rigorous during the waves conducted during the outbreak. Calculating baseline closure rates, as a result, would effectively bias our results to show larger-than-actual effects as a result of Ebola.

${ }^{v}$ While we prefer the current approach to clustering at the county level (the level at which the treatment varies) because only 9 counties appear in our data, clustering at the county level has only minor effects on the size of the standard errors of our estimates.
} 


\section{Other topics}

Table 3 Regression results

\begin{tabular}{|c|c|c|c|c|c|c|}
\hline Variables & $\begin{array}{l}\text { (I) } \\
\text { (OLS) Employees } \\
\text { per firm (log) }\end{array}$ & $\begin{array}{l}\text { (II) } \\
\text { (OLS) Employees } \\
\text { per firm (log) }\end{array}$ & $\begin{array}{l}\text { (III) } \\
\text { (Tobit) Employees } \\
\text { per firm (log) }\end{array}$ & $\begin{array}{l}\text { (IV) } \\
\text { (OLS) Won contract } \\
\text { in the past } 6 \text { months } \\
\text { ( } p \text { value) }\end{array}$ & $\begin{array}{l}\text { (V) } \\
\text { (OLS) Won contract } \\
\text { in the past } 6 \text { months } \\
\text { ( } p \text { value) }\end{array}$ & $\begin{array}{l}\text { (VI) } \\
\text { (Logit) Won contract } \\
\text { in the past } 6 \text { months } \\
\text { ( } p \text { value) }\end{array}$ \\
\hline Outbreak & $\begin{array}{l}-0.27^{* * *} \\
(0.10)\end{array}$ & $\begin{array}{l}-0.26^{\star *} \\
(0.11)\end{array}$ & $\begin{array}{l}-0.31^{* * *} \\
(0.12)\end{array}$ & $\begin{array}{l}-0.30^{* * *} \\
(0.07)\end{array}$ & $\begin{array}{l}-0.26^{* * *} \\
(0.08)\end{array}$ & $\begin{array}{l}-1.33^{* * *} \\
(0.30)\end{array}$ \\
\hline Outbreak×Montserrado & $\begin{array}{l}-0.36^{* * *} \\
(0.14)\end{array}$ & $\begin{array}{l}-0.34^{* *} \\
(0.15)\end{array}$ & $\begin{array}{l}-0.40^{* *} \\
(0.16)\end{array}$ & $\begin{array}{l}-0.19^{* *} \\
(0.09)\end{array}$ & $\begin{array}{l}-0.13 \\
(0.11)\end{array}$ & $\begin{array}{l}-0.86^{* *} \\
(0.41)\end{array}$ \\
\hline $\begin{array}{l}\text { Outbreakxhighly affected } \\
\text { counties }\end{array}$ & $\begin{array}{l}0.13 \\
(0.13)\end{array}$ & $(0.13)$ & $(0.14)$ & $\begin{array}{l}-0.12 \\
(0.09)\end{array}$ & $\begin{array}{l}-0.07 \\
(0.11)\end{array}$ & $\begin{array}{l}-0.63 \\
(0.41)\end{array}$ \\
\hline Montserrado & $\begin{array}{l}0.08 \\
(0.11)\end{array}$ & & $\begin{array}{l}0.08 \\
(0.12)\end{array}$ & $\begin{array}{l}0.15^{*} \\
(0.08)\end{array}$ & & $\begin{array}{l}0.65^{*} \\
(0.35)\end{array}$ \\
\hline Highly affected counties & $\begin{array}{l}-0.23^{* *} \\
(0.12)\end{array}$ & & $\begin{array}{l}-0.26^{* *} \\
(0.12)\end{array}$ & $\begin{array}{l}0.06 \\
(0.08)\end{array}$ & & $\begin{array}{l}0.24 \\
(0.34)\end{array}$ \\
\hline Observations & 1349 & 1349 & 1349 & 914 & 914 & 914 \\
\hline Quarter FE? & Yes & Yes & Yes & Yes & Yes & Yes \\
\hline Firm FE? & No & Yes & No & No & Yes & No \\
\hline Number of firms & 337 & 337 & 337 & 334 & 334 & 334 \\
\hline
\end{tabular}

down. And of the firms in the more-affected counties, $8 \%$ have closed down. To get a sense of perspective, Aga and Francis ${ }^{9}$ use the World Bank Enterprise Surveys to find annual firm closure rates in Africa to be around 5\% per annum, ranging from $<1 \%$ in Uganda to $11 \%$ in Ghana. The Monrovia closure rate appears unusually high.

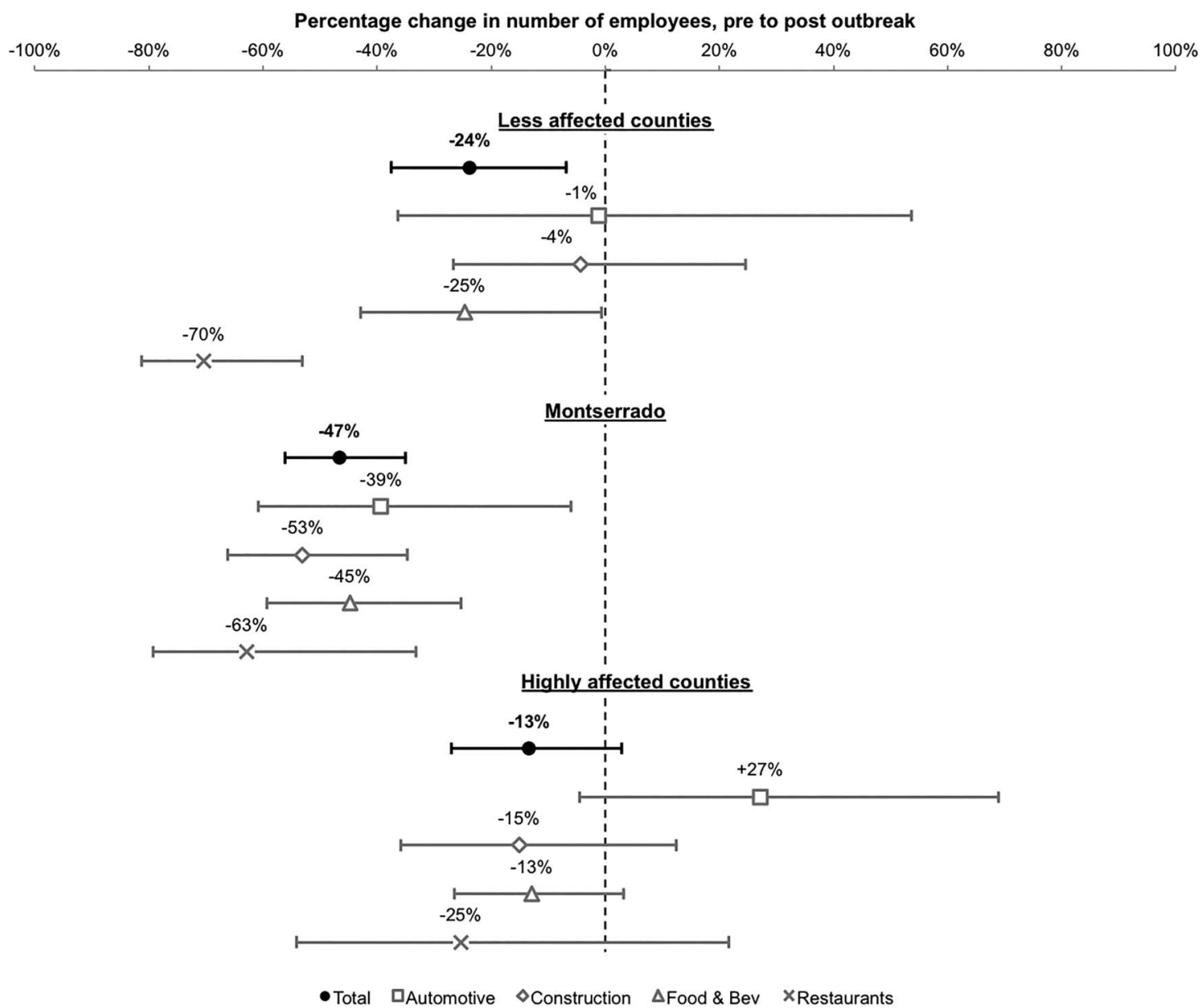

Figure 2 Plotting percentage change from employment outcome variable, by sector. Black circle: total. Square: automotive. Diamond: construction. Triangle: food and beverages (Food \& Bev). Cross: restaurants. 


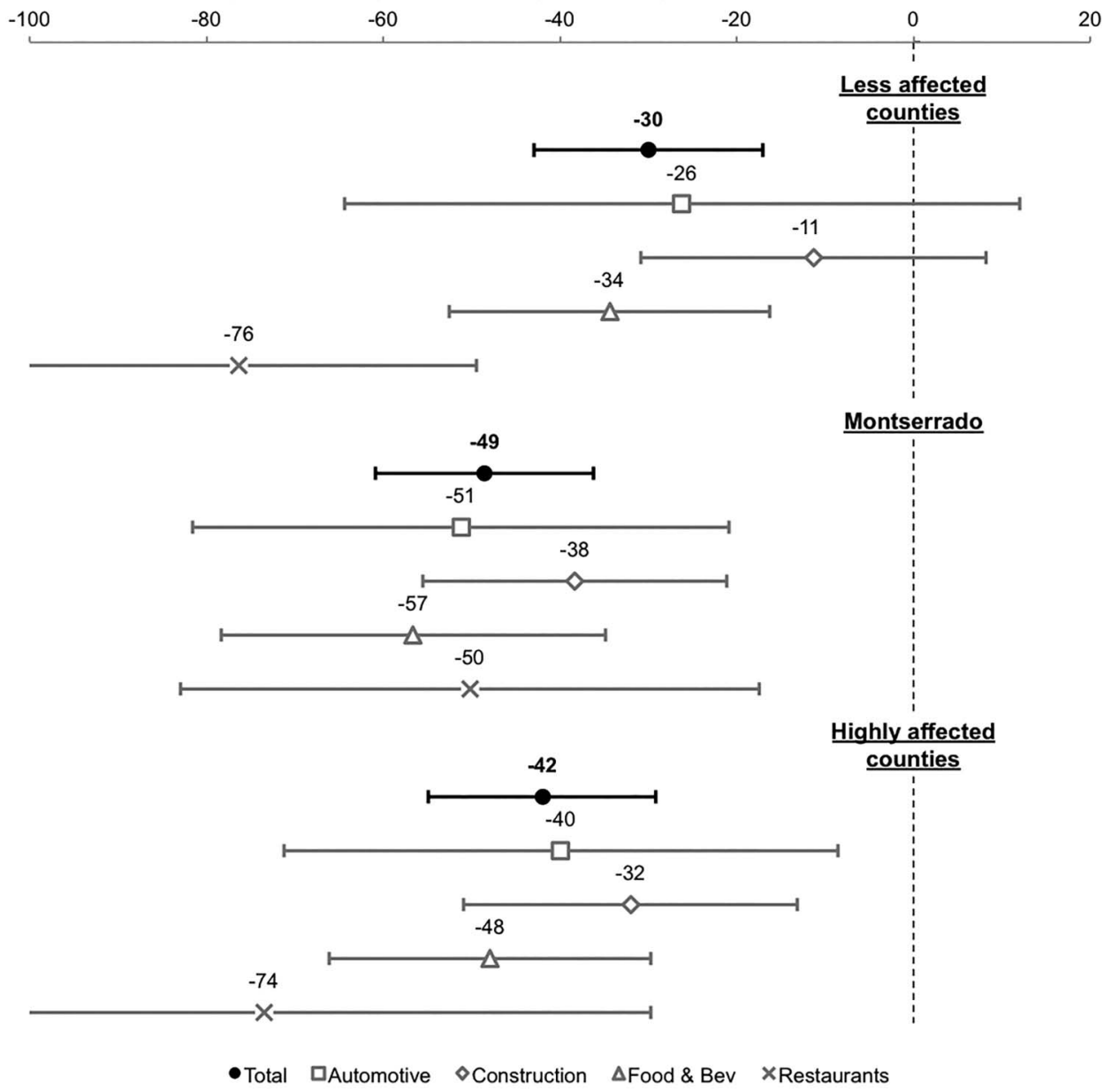

Figure 3 Plotting coefficients from contracts outcome variable, by sector. Black circle: total. Square: automotive. Diamond: construction. Triangle: food and beverages (Food \& Bev). Cross: restaurants.

Using pairwise equality of proportions $t$ tests, significantly more firms have closed in Montserrado than either the less-affected counties $(p=0.04)$ or the most-affected counties $(p=0.01)$. There is no significant difference in the number of closed firms across less-affected and most-affected counties $(p=0.61)$. $^{\mathrm{vi}}$

\section{Number of employees per firm}

The number of people employed per firm in Liberia's less-affected counties has fallen statistically significantly by $24 \%$ (based on the untransformed coefficient on Outbreak of -0.271 $(p=0.008)$ in column I). Firms in Montserrado have seen a $47 \%$ decrease in average employment per firm compared to before the crisis. This is statistically significantly worse than firms in the less-affected counties (based on the untransformed coefficient of -0.371 in column I of table 3). Firms in the most-affected counties have seen statistically insignificant decreases of $13 \%$. These decreases are also insignificantly different to the decreases in less-affected counties. The robustness

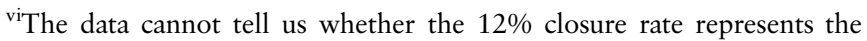
country's baseline rate or an elevated rate due to the EVD outbreak; because of this challenge in interpretation, which affects all three of our outcome variables, we report both the first difference (eg, before and after the outbreak) and second difference (more affected counties and Montserrado compared to less affected counties).
}

checks of specifications II and III give no reason to question the results of our primary specification.

Figure 2 depicts the regional results for particular sectors, expressed in the percentage change in employees per firm comparing post-outbreak with pre-outbreak. We plot 95\% CIs for the whole sample of firms (black circle), automotive firms (square), construction firms (diamond), food and beverage firms (triangle), and restaurants (cross). The coefficients are based on the same regression specification as column I in table 3.

In less-affected counties, food and beverages firms have seen a significant decrease of $25 \%$ in employment. Restaurants have seen a significant decrease of $70 \%$, driven largely by the comparatively high proportion of restaurants that have closed compared to other sectors. Automotive and construction firms have seen insignificant changes in the less-affected counties. In Montserrado, all sectors have seen significant decreases in employment-in automotives by $39 \%$, in construction by $53 \%$, in food and beverages by $45 \%$, and among restaurants by $63 \%$. Among these, only construction firms had statistically significantly worse numbers in Montserrado compared to in less-affected countries. There are no statistically significant differences in employees in the more-affected counties when comparing pre-Ebola and post-Ebola, nor significant differences in any given sector between the more-affected and less-affected counties-except that restaurants in the less-affected counties were worse off than in the more-affected counties. 


\section{Firm won contract in last six months}

The significant coefficient of $-0.3(\mathrm{p}<0.0001)$ on Outbreak in column IV indicates that the proportion of firms winning contracts has decreased by 30 percentage points in the less-affected counties since the crisis. In Montserrado, firms are hit even harder: the proportion of firms winning contracts has fallen by 49 percentage points, with the difference statistically significant. Firms in more-affected counties have seen decreases of 42 percentage points, which is insignificantly different to firms in less-affected counties. Figure 3 provides a graphical representation of the sectoral impact. The results are based on the same regression specification as column IV in table 3 . The interpretation here is slightly different, with percentage point changes in the probability of winning a contract, compared to percentage change in figure 2. Automotive firms and construction firms have seen insignificant decreases in their probability of winning contracts in less-affected counties. Firms in the food and beverages industry have seen a significant fall of 34 percentage points, while restaurants have seen a large and significant decrease of 76 percentage points. This, again, is due to the high proportion of restaurants that have closed in less-affected counties.

In Montserrado, automotive firms have seen significant decreases of 51 percentage points, construction firms of 38 percentage points, food and beverages firms of 57 percentage points and restaurants of 50 percentage points. Among these, only the construction sector has been significantly worse-affected than those firms in less-affected counties. In the more-affected counties, automotive firms have seen decreases of 40 percentage points, construction firms of 32 percentage points, food and beverages firms of 48 percentage points, and restaurants of 74 percentage points. No sectors in the most-affected counties have been affected significantly differently compared to those in the less-affected counties.

\section{INTERPRETATION}

In this analysis, we have used a pre-Ebola outbreak baseline of data on jobs and economic activity in registered firms in Liberia. We collected the same information from the same firms during the outbreak, which allows us to estimate the change in economic outcomes, and compare it across sectors and regions, to better understand the decline in economic activity during the Ebola period.

Our results point to two main conclusions. First, there was a large, first-order decrease in economic activity during the Ebola outbreak across all of Liberia. Second, the county of Montserrado (where Monrovia and most of the formal privatesector activity are located) has been hit significantly harder, economically, than other regions. Outside the capital, there is little relationship between the health and economic burden of the crisis. This suggests that Ebola should be seen as a nation-wide economic shock, the local impact of which is only weakly correlated with proximate Ebola cases.

The sectoral results suggest that, outside of Monrovia, the restaurants, and food and beverages sectors have suffered the most among the surveyed sectors, and in Monrovia the construction and restaurant sectors have shed the most employees, while the food and beverages sector experienced the largest drop in new contracts.

These findings indicate that the efforts to rebuild and support the healthcare system should be complemented by well-targeted efforts to support the region's economic recovery. If firms that might go out of business due to the Ebola shock but would otherwise be a going concern could be saved, an economic policy response could be a good investment of taxpayer money.
That said, the findings do not lead immediately to the conclusion that targeting should respond to initial Ebola impact, nor that support to individual firms will contribute to Liberia's recovery. For example, some of the closed firms may have re-opened (or the entrepreneur behind the firm may have started a new business). It may also be the case that a rebound in the economy from the resolution of the outbreak will re-energise some sectors faster than others. More research is needed on these questions.

Additionally, since our results are derived from a sample of registered firms, they are informative only about firms in the formal sector with a chance of being involved in a global supply chain. These firms might be more robust than informal-sector firms given their greater capabilities and resources. Conversely, these firms might be more sensitive to changes in the overall economic environment. Further research would be needed to extrapolate to a national estimate.

Finally, the results point to limitations of a difference-in-differences approach using within-country variation for evaluating the impact of a shock with both national and local implications. It appears from the data that the Ebola outbreak led to as much or more economic damage in cyclical sectors such as restaurants and construction as it did in the regions suffering worst from the shock. There is thus no clean control group that can be used to establish the 'pure' counterfactual of what would have happened in the absence of the Ebola shock.

\section{What is already known on this subject}

The existing literature finds that (1) jobs and economic activity matter for long-term health ${ }^{7}$ and (2) epidemics can have large immediate effects on economic activity, and potentially also long-term effects. ${ }^{4-6}$ In Liberia, agricultural markets have been profoundly affected ${ }^{3}$ and the macroeconomy is forecasted to contract substantially. ${ }^{2}$ Yet there is, to the best of our knowledge, no existing evidence on the magnitude of the economic downturn during the Ebola outbreak measured at the firm level-the level at which economic activity takes place.

\section{What this study adds}

The present study is unique in that we have access to data from a fairly large sample of firms surveyed both before and while Ebola occurred. This allows us to estimate changes in firm-level economic activity during the outbreak and to compare the magnitude of the economic downturn across sectors and across regions of Liberia with more versus fewer Ebola cases.

Contributors $\mathrm{JH}$ and EW substantially contributed to the conception and design of the work, analysis and interpretation of data for the work, drafting and revising the work, and final approval of the version to be published. JB substantially contributed to the analysis and interpretation of data for the work, and drafting and revising the work. TM substantially contributed to the acquisition of data for the work.

Funding International Growth Centre, funding award \#51202.

Competing interests $\mathrm{JH}$ and $\mathrm{EW}$ are employed part-time, respectively, as Lead Academic and Country Director of the Liberia Country programme of the International Growth Centre (IGC) (http://www.theigc.org/), which funded the research. JB was, at the time of writing, employed full-time by IGC. TM is the Liberia Country director for Building Markets, the data of which is used in the research. 
Provenance and peer review Not commissioned; externally peer reviewed.

Open Access This is an Open Access article distributed in accordance with the Creative Commons Attribution Non Commercial (CC BY-NC 4.0) license, which permits others to distribute, remix, adapt, build upon this work non-commercially, and license their derivative works on different terms, provided the original work is properly cited and the use is non-commercial. See: http://creativecommons.org/ licenses/by-nc/4.0/

\section{REFERENCES}

1 Toweh A, Farge E. Liberia confirms new Ebola case as outbreak spreads. Reuters. http://www.reuters.com/article/2015/07/14/us-health-ebola-idUSKCNOPO1EN 20150714 (accessed 14 Jul 2015).

2 Thomas MR, Smith G, Ferreira FHG, The economic impact of Ebola on sub-Saharan Africa: updated estimates for 2015. Washington DC: World Bank Group, 2015. http://documents.worldbank.org/curated/en/2015/01/23831803/economic-impactEbola-sub-saharan-africa-updated-estimates-2015 (accessed 19 Mar 2015).
3 Glennerster R, Suri T. The implications of the Ebola outbreak on markets, traders, and food security in Sierra Leone. http://www.theigc.org/wp-content/uploads/2015/ 01/Economic-Impact-of-Ebola-Bulletin-Two2.pdf (accessed 19 Mar 2015).

4 Kalemli-Ozcan S. AIDS, "reversal" of the demographic transition and economic development: evidence from Africa. J Popul Econ 2010;25:871-97.

5 Evans D, Miguel E. Orphans and schooling in Africa: a longitudinal analysis. Demography 2007;44:35-57.

6 Thirumurthy H, Zivin JG, Goldstein M. The economic impact of AIDS treatment: labor supply in western Kenya. J Hum Resour 2008;43:511-52.

7 Cutler D, Deaton A, Lleras-Muney A. The determinants of mortality. J Econ Perspect 2006;20:97-120

8 Stuckler D, Basu S, Suhrcke M, et al. The public health effect of economic crises and alternative policy responses in Europe: an empirical analysis. Lancet 2009;374:315-23.

9 Aga G, Francis D. As the market churns: estimates of firm exit and job loss using the World Bank's Enterprise Surveys. World Bank Policy Research Working Paper 7218. 